\title{
PEMANFAATAN SARANA TEMU KEMBALI INFORMASI DI PERPUSTAKAAN UNIVERSITAS BUNG HATTA
}

\author{
Fitrah Ramadhan*), Marlini**) \\ Program Studi Informasi Perpustakaan dan Kearsipan \\ Jurusan Bahasa dan Sastra Indonesia dan Daerah \\ Fakultas Bahasa dan Seni Universitas Negeri Padang Indonesia \\ Email: fitrahramadhan219@gmail.com
}

Naskah diterima: 13 November ; direvisi: 28 November ; disetujui: 13 Desember 2020.

\begin{abstract}
Abstrak
Sarana temu kembali informasi yang dimiliki perpustakaan di Universitas Bung Hatta adalah OPAC yaitu fasilitas yang mengimplementasikan sistem online, fasilitas ini berupa satu atau beberapa komputer (PC) yang disediakan oleh perpustakaan yang dapat digunakan oleh semua pengguna untuk melakukan browsing perpustakaan. katalog yang sudah berbentuk pangkalan. data elektronik. Katalog akses publik online (OPAC) pada dasarnya memberikan manfaat lebih dalam memulihkan informasi di perpustakaan. pemanfaatan fasilitas temu kembali informasi oleh pengguna perpustakaan di lingkungan Universitas Bung Hatta dengan memanfaatkan kebutuhan, motif dan kepentingan. OPAC diketahui beberapa pengguna di Perpustakaan Bung Hatta dari pencarian di internet dan bertanya kepada teman. Motif siswa menggunakan OPAC adalah untuk mendapatkan koleksi buku yang mereka cari. pada indikator ketertarikan untuk menggunakan fasilitas OPAC yaitu untuk memudahkan pencarian informasi.
\end{abstract}

Kata kunci: OPAC, sarana, dan fasilitas.

\begin{abstract}
the means of retrieval of information owned by the library at Bung Hatta University is OPAC, a facility that implements an online system, this facility is one or several computers (PCs) provided by the library which can be used by all users to browse the library catalog which is already in the form of a base. electronic data. Online public access catalog (OPAC) basically provides more benefits in recovering information in the library. the use of information retrieval facilities by library users at Bung Hatta University by using needs, motives and interests. OPAC is known to some users at Bung Hatta Library from searching the internet and asking friends. The motive of students using OPAC is to get the collection of books they are looking for. on the indicator of interest in using OPAC facilities, namely to facilitate information retrieval.
\end{abstract}

Keywords: $O P A C$, means, and amenities.

\section{PENDAHULUAN}

Pemanfaatan koleksi adalah suatu penggunaan untuk memaanfatkan koleksikoleksi yang ada di perpustakaan, pemanfaatan dapat menunjang kegiatan pembelajaraan untuk mencapai kebutuhan informasi yang dicari atau diinginkan

Hastuti (2017) menjelaskan pemanfaatan koleksi perpustakaan adalah suatu proses dan kegiatan yang dilakukan oleh pemustaka dalam memanfaatkan koleksi atau informasi yang ada pada perpustakaan untuk memenuhi kebutuhan informasinya yang dibutuhkan oleh pemustaka.

Menurut Hartini (2019 : 18) menjelaskan Sarana dan prasarana perpustakaan adalah semua alat-alat, perlengkapan dan perabot ataupun inventaris yang ada di sebuah perpustakaan. Setiap perpustakaan memiliki sarana dan prasarana yang berbeda jumlahnya, tergantung jenis perpustakaan itu sendiri.

Wati (2018: 11) mendefenisikan sistem temu kembali informasi merupakan suatu sistem 
yang bertujuan untuk memanggil dan menempatkan dokumen dari/dalam basis data sesuai dengan permintaan dan keinginan pengguna.

Yusrawati (2017: 54) menegaskan tujuan utama temu balik informasi adalah menemukan kembali dokumen yang berisi informasi yang relevan dan sesuai kebutuhan pemustaka. Diketahui bahwa temu balik informasi merupakan proses menemukan kembali informasi dalam sistem penyimpanan melalui alat penelusuran guna memperoleh informasi relevan dan sesuai dengan query yang dicari pemustaka.

\section{METODE PENELITIAN}

Metode penelitian yang digunakan dalam penulisan makalah tugas akhir ini adalah menggunakan penelitian wawancara dan dokumentasi serta penelitian deskriptif yaitu penelitian yang bertujuan mendeskripsikan atau menjelaskan sesuatu hal apa adanya. Teknik pengumpulan data dalam penelitian itu dengan cara penyebaran angket, yaitu teknik pengumpulan data yang dilakukan dengan memeri pertanyaan-pertanyaan kepada responden untuk dijawabnya.

\section{HASIL DAN PEMBAHASAN}

\section{Sarana Temu Kembali Informasi Yang Dimiliki Oleh Perpustakaan Di Universitas Bung Hatta}

Sarana temu kembali informasi yang digunakan dalam mencari informasi yang ada di Perpustkaan Universitas Bung Hatta yaitu OPAC yaitu sarana yang menerapkan sistem online, sarana ini adalah salah satu atau beberapa computer (PC) yang disediakan perpustakaan yang dapat digunakan oleh semua pengguna untuk menelusur katalog perpustakaan yang sudah berbentuk pangkalan data elektronik. Online public accses catalog (OPAC) pada dasarnya lebih banyak memberikan manfaat dalam penemuan kembali informasi diperpustakaan.

\section{Pemanfaatan Sarana Temu Kembali Informasi Oleh Pemustaka Di Perpustakaan Universitas Bung Hatta \\ Pemanfaatan sarana temu kembali} informasi, tentang kebutuhan pengguna di Perpustakaan Universitas Bung Hatta yang dilihat dari pengetahuan OPAC, penggunaan OPAC, frekuensi pengakses an OPAC, OPAC sebagai pencari informasi, penggunaan OPAC.

\section{Kebutuhan Pengguna}

Pada tabel di bawah ini, dijelaskan mengenai gambaran umum tentang seberapa tau pengguna mengenai alat temu kembali informasi OPAC yang ada di Perpustakaan Universitas Bung Hatta.

Tabel 1. Mengetahui OPAC yang ada di Perpustakaan

\begin{tabular}{ccc}
\hline Kriteria Jawaban & F & \% \\
\hline Saat Mengunjungi & 7 & 22,6 \\
Perpustakaan & 12 & 38,7 \\
Searching di Internet & 12 & 38,7 \\
Bertanya Kepada & 12 & 0 \\
Teman & 0 & $\mathbf{1 0 0} \%$ \\
\hline Lainnya & $\mathbf{3 1}$ &
\end{tabular}

Sumber: Data Primer Penelitian Tahun 2020

Menurut data pada tabel tersebut dengan pertanyaan bagaimana mengetahui OPAC yang ada diperpustakaan, dengan kriteria jawaban saat mengunjungi perpustakaan 7 responden dengan hasil persentase 22,60\%, kriteria jawaban searching di internet 12 responden dengan hasil persentase 38,70 \%, kriteria jawaban bertanya kepada teman 12 responden dengan hasil persentase 38,70 \%, kriteria jawaban lainnya responden 0 .

Jadi dapat diambil kesimpulan dari data diatas bahwa kriteria jawaban searching di internet dan bertanya kepada teman lebih banyak dibandingkan dengan jawaban lainnya dengan hasil 12 responden dan hasil persentase $38,70 \%$. Jadi artinya responden mengetahui OPAC searching di internet dan bertanya kepada teman.

Pada tabel 2 dibawah ini, dijelasakan mengenai gambaran umum tentang tujuan penggunaan OPAC yang ada di Perpustakaan Universitas Bung Hatta.

Tabel 2. Penggunaan OPAC

\begin{tabular}{ccc}
\hline Kriteria Jawaban & F & $\mathbf{\%}$ \\
\hline $\begin{array}{c}\text { Untuk mencari referensi } \\
\text { dalam memenuhi tugas } \\
\text { perkulihan }\end{array}$ & 11 & 35,5 \\
$\begin{array}{c}\text { Mencari koleksi bahan } \\
\text { pustaka yang tidak } \\
\text { ditemukan di rak } \\
\text { penyimpanan }\end{array}$ & 10 & 32,3 \\
$\begin{array}{c}\text { Untuk mencari referensi } \\
\text { koleksi bahan pustaka dalam } \\
\text { menyelesaikan tugas } \\
\text { akhir/skripsi } \\
\text { Lainnya }\end{array}$ & 10 & 32,3 \\
\hline Jumlah & 0 & 0 \\
\hline
\end{tabular}

Sumber: Data Primer Penelitian Tahun 2020 
Menurut data pada tabel tersebut dengan pertanyaan tujuan pengunaan OPAC yang ada diperpustakaan, dengan kriteria jawaban untuk mencari referensi dalam memenuhi tugas perkulihan 11 responden dengan hasil persentase 35,5\%, kriteria jawaban mencari koleksi bahan pustaka yang tidak ditemukan di rak penyimpanan 10 responden dengan hasil persentase 32,3\%, kriteria jawaban Untuk mencari referensi koleksi bahan pustaka dalam menyelesaikan tugas akhir/skripsi 10 responden 10 dengan hasil 32,3 \%, kriteria jawaban lainnya responden 0 .

Jadi dapat diambil kesimpulan dari data diatas bahwa kriteria mencari koleksi bahan pustaka yang tidak ditemukan di rak penyimpanan dan untuk mencari referensi koleksi bahan pustaka dalam menyelesaikan tugas akhir/skripsi lebih banyak dibandingkan dengan jawaban lainnya dengan hasil responden 10 dengan hasil persentase 32,3\%. Jadi artinya responden tujuan penggunaan OPAC yaitu mencari koleksi bahan pustaka yang tidak ditemukan di rak penyimpanan dan Untuk mencari referensi koleksi bahan pustaka dalam menyelesaikan tugas akhir/skripsi.

Pada tabel 3 dibawah ini, dijelasakan mengenai gambaran umum tentang frekuensi kunjungan penggunaan OPAC yang ada di Perpustakaan Universitas Bung Hatta.

\begin{tabular}{ccc}
\multicolumn{3}{c}{$\begin{array}{c}\text { Tabel 3. Frekuensi Kunjungan } \\
\text { Pengguna OPAC }\end{array}$} \\
\hline Kriteria Jawaban & F & \% \\
\hline Sangat Sering & 12 & 38,7 \\
Sering & 11 & 35,5 \\
Jarang & 7 & 22,6 \\
Tidak Pernah & 1 & 3,2 \\
\hline Jumlah & $\mathbf{3 1}$ & $\mathbf{1 0 0} \%$ \\
\hline
\end{tabular}

Sumber: Data Primer Penelitian Tahun 2020

Menurut data pada tabel tersebut dengan pertanyaan frekuensi kunjungan pengguna OPAC yang ada diperpustakaan, dengan kriteria jawaban sangat sering 12 responden dengan hasil persentase $38,7 \%$, kriterian jawaban sering 11 responden dengan hasil persentase 35,5\%, kriteria jawaban jarang 7 responden dengan hasil persentase $22,6 \%$, kriteria jawaban tidak pernah 1 responden dengan hasil persentase 3,2 $\%$.

Jadi dapat diambil kesimpulan dari data diatas bahwa kriteria frekuensi kunjungan penggunaan sangat sering dengan hasil responden 12 dengan hasil persentase 38,7\%, jadi artinya frekuensi kunjungan pengguna sangat sering dalam penggunaan OPAC.

Tabel 4. OPAC Informasi Yang Dicari Dapat Ditemukan

\begin{tabular}{ccc}
\hline Kriteria Jawaban & $\mathbf{F}$ & $\mathbf{\%}$ \\
\hline Iya & 17 & 54,8 \\
Kadang-kadang & 14 & 45,2 \\
Tidak & 0 & 0 \\
\hline Jumlah & $\mathbf{3 1}$ & $\mathbf{1 0 0} \%$ \\
\hline Sumber: Data Primer Penelitian Tahun 2020
\end{tabular}

Menurut pada tabel tersebut dengan pertanyaan penggunaan OPAC informasi dapat ditemukan, dengan kriteria jawaban iya 17 responden dengan hasil persentase 54,8\%, kriteria jawaban kadang-kadang 14 dengan hasil responden 45,2 \%, kriteria jawaban tidak 0 responden.

Jadi dapat diambil kesimpulan dari data diatas bahwa kriteria penggunaan OPAC informasi dapat ditemukan, dengan kriteria jawaban iya 17 responden dengan hasil persentase $54,8 \%$, jadi artinya iya dengan menggunakan OPAC informasi yang dicari dapat ditemukan.

Tabel 5. Penggunaan OPAC Untuk Mencari Koleksi

\begin{tabular}{ccc}
\hline Kriteria Jawaban & $\mathbf{F}$ & $\mathbf{\%}$ \\
\hline Sangat Sering & 7 & 22,6 \\
Sering & 16 & 51,6 \\
Jarang & 8 & 25,8 \\
Tidak Pernah & $\mathbf{0}$ & $\mathbf{0}$ \\
\hline Jumlah & $\mathbf{3 1}$ & $\mathbf{1 0 0} \%$ \\
\hline Sumber: Data Primer Penelitian Tahun 2020
\end{tabular}

Menurut pada tabel tersebut dengan pertanyaan penggunaan OPAC untuk mencari koleksi dengan kriteria jawaban sangat sering 7 responden dengan hasil persentase 22,6\%, kriteria jawaban sering 16 responden dengan hasil persentase 51,6\%, kriteria jawaban jarang 8 responden dengan hasil persentase 25,8\%, kriteria jawaban tidak pernah 0 .

Jadi dapat diambil kesimpulan dari data diatas bahwa, dengan kriteria pertanyaan penggunaan OPAC untuk mencari koleksi jawaban sering 16 responden dengan hasil persentase $51,6 \%$, jadi artinya penggunaan OPAC sering dilakukan oleh mahasiswa Bung Hatta. 


\section{Motif Pengguna}

Pada tabel di bawah ini, dijelaskan mengenai gambaran umum motif dalam penggunaan OPAC motif pengguna yang membuat mahasiswa termotivasi untuk berkunjung dalam menggunakan OPAC sebagai alat temu kembali informasi.

Tabel 6. Penyebab Penggunaan OPAC

\begin{tabular}{ccc}
\multicolumn{3}{c}{ Tabel 6. Penyebab Penggunaan } \\
\hline Kriteria Jawaban & F & $\mathbf{\%}$ \\
\hline $\begin{array}{c}\text { Ingin mendapatkan koleksi } \\
\text { buku yang dicari }\end{array}$ & 18 & 58,1 \\
$\begin{array}{c}\text { Memenuhi kebutuhan } \\
\text { informasi dengan cepat, } \\
\text { akurat dan relevan } \\
\text { Informasi yang kurang } \\
\text { memadai ketika } \\
\text { penelusuran di rak } \\
\text { Lainnya }\end{array}$ & 10 & 32,3 \\
\hline Jumlah & 3 & 9,7 \\
\hline
\end{tabular}

Sumber: Data Primer Penelitian Tahun 2020

Menurut pada tabel tersebut dengan pertanyaan motivasi penggunaan OPAC dengan kriteria jawaban ingin mendapatkan koleksi buku yang dicari 18 responden dengan hasil persentase 58,1, kriteria jawaban memenuhi kebutuhan informasi dengan cepat, akurat dan relevan 10 responden dengan hasil persentase $32,3 \%$, kriteria jawaban informasi yang kurang memadai ketika penelusuran di rak 3 responden dengan hasil responden 9,7\%, kriteria jawaban lainnya 0 responden.

Jadi dapat diambil kesimpulan dari data diatas bahwa, dengan kriteria pertanyaan motovasi pengguna dalam menggunakan OPAC ingin mendapatkan koleksi buku yang dicari lebih banyak dibandingkan dengan jawaban lainnya dengan hasil responden 18 dengan hasil persentase $58,1 \%$. Jadi artinya motivasi penggunaan OPAC oleh mahasiswa Universitas Bung Hatta ingin mendapatkan koleksi buku yang dicari.

Tabel 7. Pengguna Bertanya Dulu Kepada Pustakawan

\begin{tabular}{ccc}
\hline Kriteria Jawaban & F & $\mathbf{\%}$ \\
\hline Sangat sering & 11 & 35,5 \\
Sering & 11 & 35,5 \\
Jarang & 9 & 29 \\
Tidak Pernah & $\mathbf{0}$ & $\mathbf{0}$ \\
\hline Jumlah & $\mathbf{3 1}$ & $\mathbf{1 0 0} \%$ \\
\hline
\end{tabular}

Sumber: Data Primer Penelitian Tahun 2020

Menurut pada tabel tersebut dengan pertanyaan dalam mengakses OPAC pengguna bertanya dulu kepada pustakawan dengan kriteria jawaban sangat sering 11 responden dengan hasil persentase 35,5\%, kriteria jawaban sering 11 responden denga $\mathrm{n}$ hasil persentase $35,5 \%$, kriteria jawaban jarang 9 responden dengan hasil persentase $29 \%$, kriteria jawaban tidak pernah 0 responden.

Jadi dapat diambil kesimpulan dari data diatas bahwa dengan kriteria pengguna sangat sering dan sering bertanya kepada pustakawan lebih banyak dibandingkan dengan jawaban lainnya dengan hasil responden 11 dengan hasil persentase $35,5 \%$. jadi artinya pengguna sangat sering dan sering dalam bertanya kepada pustkawan.

Tabel 8. Penggunaan OPAC Dalam Menelusuri Koleksi Yang Diakses

\begin{tabular}{ccc}
\hline Kriteria Jawaban & F & $\mathbf{\%}$ \\
\hline Majalah, atau Surat Kabar & 4 & 12,9 \\
Buku & 9 & 29 \\
Tugas Akhir, Skripsi, Tesis & 11 & 35,5 \\
Jurnal dan Artikel & 7 & 22,6 \\
\hline Jumlah & $\mathbf{3 1}$ & $\mathbf{1 0 0} \%$ \\
\hline
\end{tabular}

Sumber: Data Primer Penelitian Tahun 2020

Menurut pada tabel tersebut dengan pertanyaan koleksi yang di akses ketika menggunakan OPAC dengan kriteria jawaban majalah, atau surat kabar 4 responden dengan hasil persentase 12,9\%, kriteria jawaban buku 9 responden dengan hasil persentase $29 \%$, kriteria jawaban tugas akhir, skripsi, tesis 11 responden dengan hasil persentase 35,5 \%, kriteria jawaban jurnal dan artikel 7 responden dengan hasil persentase $22,6 \%$.

Jadi dapat diambil kesimpulan dari data diatas bahwa dengan kriteria jawaban tugas akhir, skripsi, tesis lebih banyak dibandingkan dengan jawaban lainnya dengan hasil responden 11 dengan hasil persentase $35,5 \%$. jadi artinya responden mengakses koleksi ketika menggunakan OPAC koleksi tugas akhir, skripsi, tesis.

\begin{tabular}{|c|c|c|}
\hline \multicolumn{3}{|c|}{$\partial$} \\
\hline Kriteria Jawaban & $\mathbf{F}$ & $\%$ \\
\hline Cukup Mengetahui & 20 & 64,5 \\
\hline Sangat Mengetahui & 6 & 19,4 \\
\hline Sedikit Mengetahui & 5 & 16,1 \\
\hline Jumlah & 31 & $100 \%$ \\
\hline
\end{tabular}


Menurut pada tabel tersebut dengan pertanyaan seberapa taunya pengguna dalam menggunakan OPAC dengan, kriteria jawaban cukup mengetahui 20 responden dengan hasil persentase $64,5 \%$, kriteria jawaban sangat mengetahui 6 responden dengan hasil persentase $19,4 \%$, kriteria jawaban sedikit mengetahui 5 responden dengan hasil persentase $16,1 \%$.

Jadi dapat diambil kesimpulan dari data diatas bahwa dengan kriteria jawaban cukup mengetahui lebih banyak dibandingkan dengan jawaban lainnya dengan hasil responden 20 dengan hasil persentase 64,5 \%. Jadi artinya mahasiswa Universitas Bung Hatta cukup mengetahui dalam menggunakan OPAC.

Tabel 10. Motivasi Pengguna dalam Menggunakan OPAC

\begin{tabular}{ccc}
\hline Kriteria Jawaban & F & \% \\
\hline $\begin{array}{c}\text { Untuk Memenuhi Kebutuhan } \\
\text { Informasi }\end{array}$ & 8 & 26,8 \\
Untuk Melengkapi Tugas & 15 & 48,4 \\
$\quad$ Perkulihan & 8 & 25,8 \\
\hline $\begin{array}{c}\text { Ingin Menambah Wawasan } \\
\text { Jumlah }\end{array}$ & $\mathbf{3 1}$ & $\mathbf{1 0 0 \%}$ \\
\hline
\end{tabular}

Sumber: Data Primer Penelitian Tahun 2020

\begin{abstract}
Menurut pada tabel tersebut dengan pertanyaan motivasi pengguna dalam menggunakan OPAC dengan kriteria jawaban untuk memenuhi kebutuhan informasi 8 responden dengan hasil persentase 26,8 \%, kriteria jawaban untuk melengkapi tugas perkuliahan 15 responden dengan hasil perentase $48,4 \%$, kriteria jawaban untuk ingin menambah wawasan 8 responden dengan hasil persentase $25,8 \%$.
\end{abstract}

Jadi dapat diambil kesimpulan dari data diatas bahwa dengan kriteria jawaban untuk melengkapi tugas perkulihan lebih banyak dibandingkan dengan jawaban lainnya dengan hasil responden 15 dengan hasil persentase 48,4 $\%$. Jadi artinya motif dalam penggunaan OPAC bagi mahasiswa Bung Hatta untuk melengkapi tugas perkulihan.

\section{Minat Pengguna}

Pada tabel di bawah ini, dijelaskan mengenai gambaran umum tentang minat pengguna mengenai alat temu kembali informasi OPAC yang ada di Perpustakaan Universitas Bung Hatta.
Tabel 11. Keinginan Menggunakan OPAC

\begin{tabular}{ccc}
\hline Kriteria Jawaban & F & $\mathbf{\%}$ \\
\hline $\begin{array}{c}\text { Untuk Mempermudah Temu } \\
\text { Kembali Informasi }\end{array}$ & 18 & 58,1 \\
$\begin{array}{c}\text { Ingin Mengetahui Jumlah Koleksi } \\
\text { Yang Terdapat Pada OPAC } \\
\text { Ingin Mengetahui Jenis-Jenis } \\
\text { Koleksi Yang Tersedia Pada OPAC }\end{array}$ & 9 & 29 \\
\hline Jumlah & $\mathbf{3 1}$ & $\mathbf{1 0 0 \%}$ \\
\hline
\end{tabular}

Sumber: Data Primer Penelitian Tahun 2020

Menurut pada tabel tersebut dengan pertanyaan keinginan menggunakan OPAC dengan kriteria jawaban untuk mempermudah temu kembali informasi 18 responden dengan hasil persentase 58,1\%, kriteria jawaban ingin mengetahui jumlah koleksi yang terdapat pada OPAC 9 responden dengan hasil persentase $29 \%$, kriteria jawaban ingin engetahui jenis- jenis koleksi yang tersedia pada OPAC 8 responden dengan hasil persentase $25,8 \%$.

Jadi dapat diambil kesimpulan dari data diatas bahwa dengan kriteria jawaban untuk mempermudah temu kembali informasi lebih banyak dibandingkan dengan jawaban lainnya dengan responden 18 dengan hasil persentase $58,1 \%$. Jadi artinya yang membuat mahasiswa ingin menggunakan OPAC yaitu untuk Mempermudah Temu Kembali Informasi.

Tabel 12. Seberapa Sering Mahasiswa Menggunakan OPAC

\begin{tabular}{ccc}
\hline Kriteria Jawaban & F & $\mathbf{0}$ \\
\hline Sangat Sering & 5 & 16,1 \\
Sering & 12 & 38,7 \\
Jarang & 11 & 25,8 \\
Cukup Sering & 1 & 3,2 \\
Tidak Pernah & 2 & 6,5 \\
\hline Jumlah & $\mathbf{3 1}$ & $\mathbf{1 0 0 \%}$ \\
\hline
\end{tabular}

Sumber: Data Primer Penelitian Tahun 2020

Menurut pada tabel tersebut dengan pertanyaan seberapa sering menggunakan OPAC dengan kriteria jawaban sangat sering 5 responden dengan hasil persentase 16,1\%, kriteria jawaban sering 12 responden dengan hasil persentase 38,7 \%, kriteria jawaban jarang 11 responden dengan hasil persentase 25,8\%, kriteria jawaban cukup sering 1 responden dengan hasil persentase 3,2 \%, kriteria jawaban tidak pernah 2 responden dengan hasil persentase $6,5 \%$.

Jadi dapat diambil kesimpulan dari data diatas bahwa dengan kriteria seberapa seringnya mahasiswa menggunakan OPAC lebih banyak dibandingkan dengan jawaban lainnya yaitu sering dengan 12 responden hasil dari persentase $38,7 \%$. jadi artinya sering nyaa 
mahassiwa menggunakan OPAC sebgaai sarana temu kembali informasi di Perpustakaan Bung Hatta.

Tabel 13. Pemahamam dalam Menggunakan OPAC

\begin{tabular}{ccc}
\hline Kriteria Jawaban & F & $\mathbf{\%}$ \\
\hline Sangat Paham & 7 & 22,6 \\
Paham & 13 & 41,9 \\
Kurang Paham & 10 & 32,3 \\
Tidak Paham & 1 & 3,2 \\
\hline Jumlah & $\mathbf{3 1}$ & $\mathbf{1 0 0} \%$
\end{tabular}

Sumber: Data Primer Penelitian Tahun 2020

Menurut pada tabel tersebut dengan pertanyaan pemahaman dalam menggunakan OPAC dengn kriteria jawaban sangat paham 7 responden dengan hasil persentase 22,6\%, kriteria jawaban paham 13 responden dengan hasil persentase $41,9 \%$, kriteria jawaban kurang paham 10 responden dengan hasil persentase $32,3 \%$, kriteria jawaban tidak paham 1 responden dengan hasil persentase 3,2 \%.

Jadi dapat diambil kesimpulan dari data diatas bahwa dengan kriteria paham lebih banyak dibandingkan dengan jawaban lainnya yaitu paham dalam menggunakan OPAC yang ada di Perpustakaan Universitas Bung Hatta. dengan 13 responden dengan hasil persentase 41,9.

Tabel 14. Informasi OPAC Relevan Dengan Yang Dibutuhkan

\begin{tabular}{ccc}
\hline Kriteria Jawaban & $\mathbf{F}$ & $\mathbf{\%}$ \\
\hline Iya & 8 & 25,8 \\
Iya, Tapi Belum & 20 & 64,5 \\
Lengkap & 3 & 9,7 \\
Belum & 0 & 0 \\
Lainnya & $\mathbf{3 1}$ & $\mathbf{1 0 0} \%$ \\
\hline Jumlah &
\end{tabular}

Sumber: Data Primer Penelitian Tahun 2020

Menurut pada tabel tersebut dengan pertanyaan Informasi yang ada di OPAC sudah relevan dengan yang dibutuhkan dengan kriteria jawaban iya 8 responden dengan hasil 25,8\%, kriteria jawaban iya, tapi belum lengkap 20 responden dengan hasil persentase 64,5\%, kriteria jawaban belum 3 responden dengan hasil persentase 9,7\%, kriteria jawaban lainnya 0 responden.

Jadi dapat diambil kesimpulan dari data diatas bahwa dengan kriteria iya, tapi belum lengkap, banyak dibandingkan dengan jawaban lainnya dengan responden 20 hasil persentase $64,5 \%$. jadi artinya informasi yang ada di OPAC iya, tetapi belum lengkap oleh mahasiswa Bung Hatta.
Tabel 15. Alasan Mahasiswa Menggunakan OPAC

\begin{tabular}{ccc}
\hline Kriteria Jawaban & F & \% \\
\hline $\begin{array}{c}\text { Untuk Melakukan Penelusuran } \\
\text { Temu Kembali Informasi }\end{array}$ & 16 & 51,6 \\
Memanfaatkan Koleksi Yang & 12 & 38,7 \\
$\begin{array}{c}\text { Terdapat Pada OPAC } \\
\text { Untuk Mencari Bahan Rujukan }\end{array}$ & 3 & 9,7 \\
\hline Jumlah & $\mathbf{3 1}$ & $\mathbf{1 0 0} \%$ \\
\hline Sumber: Data Primer Penelitian Tahun 2020
\end{tabular}

Menurut pada tabel tersebut dengan pertanyaan alasan mahasiswa mnggunakan OPAC dengan, kriteria jawaban untuk melakukan penelusuran temu kembali informasi 16 responden dengan hasil 52,6\%, kriteria jawaban memanfaatkan koleksi yang terdapat pada OPAC 12 responden dengan hasil persentase $38,7 \%$, kriteria jawaban untuk mencari bahan rujukan 3 responden dengan hasil persentase $9,7 \%$.

Jadi dapat diambil kesimpulan dari data diatas bahwa dengan kriteria untuk melakukan penelusuran temu kembali informasi lebih banyak dibandingkan dengan jawaban lainnya dengan responden 51,6 \%. Jadi artinya alasan mahasiswa menggunakan OPAC yaitu untuk melakukan penelusuran temu kembali informasi.

Pendapat Pemustaka Terhadap Sarana Temu Kembali Informasi Yang Tersedia Oleh Perpustakaan Di Universitas Bung Hatta.

Pada bagian ini, dijelaskan mengenai pendapat pemustaka terhadap sarana temu kembali informasi yang tersedia oleh perpustakaan di Universitas Bung Hatta. yang dilihat dari informasi pada OPAC dapat membantu dalam memenuhi kebutuhan informasi mahasiswa Univeritas Bung Hatta, Informasi yang ad pada OPAC sudah akurat, opac mudah dalam akses memenuhi kebutuhan informasi, penggunaan OPAC berhubungan dengan kuliah, apakah OPAC untuk sarana hiburan. Selanjutnya membahas hasil penyebaran kuesioner dari 31 responden yang berisikan pertanyaan-pertanyaan mengenai pendapat pemustaka terhadap sarana temu kembali informasi yang tersedia oleh Perpustakaan Di Universitas Bung Hatta.

Tabel 16. OPAC Membantu

Dalam Memenuhi Kebutuhan

\begin{tabular}{ccc}
\hline Kriteria Jawaban & F & \% \\
\hline Iya & 6 & 19,4 \\
Mungkin & 20 & 64,5 \\
Tidak & 5 & 16,1 \\
Lainnya & 0 & 0 \\
\hline Jumlah & $\mathbf{3 1}$ & $\mathbf{1 0 0} \%$ \\
\hline
\end{tabular}

Sumber: Data Primer Penelitian Tahun 2020 
Menurut pada tabel tersebut dengan pertanyaan OPAC membantu dalam memenuhi kebutuhan dengan, kriteria jawaban iya 6 responden dengan hasil 19,4\%, kriteria jawaban mungkin 20 responden dengan hasil persentase 64,5 \%, kriteria jawaban tidak 5 responden dengan hasil persentase $16,1 \%$, kriteria jawaban lainnya 0 responden.

Jadi dapat diambil kesimpulan dari data diatas bahwa dengan kriteria mungkin lebik banyak dibandingkan dengan jawaban lainnya dengan responden 20 hasil persentase 64,5\%. Jadi artinya OPAC mungkin membantu memenuhi informasi yang diinginkan.

\begin{tabular}{ccc}
\multicolumn{3}{c}{$\begin{array}{c}\text { Tabel 17. OPAC Sudah Menyediakan } \\
\text { Informasi Yang Akurat }\end{array}$} \\
\hline Kriteria Jawaban & F & $\mathbf{\%}$ \\
\hline Iya & 4 & 12,9 \\
Sudah & 17 & 54,8 \\
Belum & 7 & 22,6 \\
Mungkin & 3 & 9,7 \\
\hline Jumlah & $\mathbf{3 1}$ & $\mathbf{1 0 0} \%$ \\
\hline
\end{tabular}

Sumber: Data Primer Penelitian Tahun 2020

Menurut pada tabel tersebut dengan pertanyaan apakah OPAC sudah menyediakan informasi yang akurat dengan, kriteria jawaban iya 4 responden 4 hasil persentase $12,9 \%$, kriteria jawaban sudah 17 responden hasil persentase 54,8 \%, kriteria jawaban belum 7 responden dengan hasil persentase 22,6\%, kriteria jawaban mungkin 3 responden dengan hasil persentasi 9,7\%.

Jadi dapat diambil kesimpulan dari data diatas bahwa dengan kriteria sudah lebih banyak dibandingkan dengan jawaban lainya dengan responden 17 hasil persentase 54,8 \%. Jadi artinya OPAC sudah menyediakan informasi yang akurat.

\section{Tabel 18. OPAC Mudah Diakses Memenuhi} Kebutuhan Informasi

\begin{tabular}{ccc}
\hline Kriteria Jawaban & F & \% \\
\hline Sudah & 15 & 48,4 \\
Belum & 10 & 32,3 \\
Kadang- kadang & 6 & 19,4 \\
\hline Jumlah & $\mathbf{3 1}$ & $\mathbf{1 0 0} \%$ \\
\hline
\end{tabular}

Sumber: Data Primer Penelitian Tahun 2020

Menurut pada tabel tersebut dengan pertanyaan OPAC mudah diakses memenuhi kebutuhan informasi dengan kriteria jawaban sudah 15 responden hasil persentase 48,4\%, kriteria jawaban belum 10 responden hasil persentase 32,3\%, kriteria jawaban kadangkadang 6 responden hasil persentase 19,4\%.

Jadi dapat diambil kesimpulan dari data diatas bahwa dengan kriteria sudah, OPAC mudah diakses untuk memenuhi kebutuhan informasi dengan responden 15 dengan persentase 48,4 . Jadi artinya OPAC sudah mudah diakses untuk memenuhi kebutuhan informasi.

\begin{tabular}{|c|c|c|}
\hline \multicolumn{2}{|c|}{$\begin{array}{c}\text { Tabel 19. OPAC Sebagai Sarana Untuk } \\
\text { Mencari Informasi Yang Berhubungan } \\
\text { Dengan Kuliah }\end{array}$} & \\
\hline Kriteria Jawaban & $\mathbf{F}$ & $\%$ \\
\hline Iya & 12 & 38,7 \\
\hline Tidak & 14 & 45,2 \\
\hline Mungkin & 5 & 16,1 \\
\hline Lainnya & 0 & 0 \\
\hline Jumlah & 31 & $100 \%$ \\
\hline
\end{tabular}

Menurut pada tabel tersebut dengan pertanyaan OPAC sebagai sarana untuk mencari informasi yang berhubungan dengn kuliah dengann kriteria jawaban iya 12 responden hasil persentase 38,7 \%, kriteria jawaban tidak 14 responden hasil persentase 45,2 \%, kriteria jawaban mungkin 5 responden hasil persentase $16,1 \%$, kriteria jawaban lainnya 0 responden.

Jadi dapat diambil kesimpulan dari data diatas bahwa dengan kriteria tidak, OPAC sebagai sarana untuk mencari informasi yang berhubungan dengan kuliah lebih banyak dibandingkan jawaban lainnya dengan responden 14 dengan hasil persentase 45,2 \%. Jadi artinya OPAC tidak digunakan sebagai sarana untuk mencari informasi kuliah.

Tabel 20. OPAC Sebagai Sarana Hiburan

\begin{tabular}{ccc}
\hline Kriteria Jawaban & $\mathbf{F}$ & $\mathbf{\%}$ \\
\hline Iya & 1 & 3,2 \\
Tidak & 15 & 48,4 \\
Mungkin & 8 & 25,8 \\
Kadang- kadang & 7 & 22,16 \\
\hline Jumlah & $\mathbf{3 1}$ & $\mathbf{1 0 0} \%$ \\
\hline Sumber: Data Primer Penelitian Tahun 2020
\end{tabular}

Menurut pada tabel tersebut dengan pertanyaan OPAC sebagai sarana hiburan dengan kriteria jawaban iya 1 reeponden hasil persentase 3,2 \%, kriteria jawaban tidak 15 responden 48,4, kriterian jawaban mungkin 8 responden hasil persentase 25,8 \%, kriteria jawaban kadang-kadang hasil persentase 22,16 $\%$. 
Jadi dapat diambil kesimpulan dari data diatas bahwa dengan kriteria tidak, OPAC sebagai sarana hiburan banyak dibandingkan dengan jawaban lainnya dengan responden 15 dengan hasil persentase 48,4\%. Jadi artinya OPAC tidak sebagai sarana hiburan.

\section{SIMPULAN}

Dalam pemanfaatan sarana temu kembali informasi di Perpustakaan Bung Hatta ada beberapa simpulan Pertama, sarana temu kembali informasi yang dimiliki oleh oleh Perpustakaan di Universitas Bung Hatta adalah OPAC, sarana yang menerapkan sistem online, sarana ini adalah salah satu atau beberapa computer (PC) yang disediakan perpustakaan yang dapat digunakan oleh semua pengguna untuk menelusur katalog perpustakaan yang sudah berbentuk pangkalan data elektronik. Online public accses catalog (OPAC) pada dasarnya lebih banyak memberikan manfaat dalam penemuan kembali informasi diperpustakaan.

Kedua, pemanfaatan sarana temu kembali informasi oleh pemustaka di Perpustakaan di Universitas Bung Hatta dengan menggunakan kebutuhan, motif, dan minat. OPAC diketahui sebagian pengguna yang ada di Perpustakaan Bung Hatta dari searching internet dan bertanya kepada teman. Motif mahasiswa menggunakan OPAC ingin mendapatkan koleksi buku yang dicari. pada indikator minat dalam menggunakan sarana OPAC yaitu untuk mempermudah temu kembali informasi. Ketiga, pendapat pemustaka terhadap sarana temu kembali informasi yang tersedia oleh Perpustakaan di Universitas Bung Hatta. OPAC bagi mahasiswa Bung Hatta mungkin membantu dalam memenuhi kebutuhan.

\section{DAFTAR PUSTAKA}

Hastuti, D. 2017. "Hubungan Sistem Temu Balik Informasi Dengan Pemanfaatan Koleksi Di Upt Perpustakaan Uin Alauddin Makassar". Skripsi. Fakultas Adab Dan Humaniora Universitas Islam Negeri Alauddin Makassar. Makasar

Hartini,G. 2019. Analisis ketersediaan sarana danprasarana perpustakaan terhadap kepuasaan pemustaka di perguruan tinggi Al-washliyah. Skrispsi. Tidak diterbitkan. fakultas Adab dan Humaniora. Universitas Islam Negeri Ar-Raniry Darusalam: Banda Aceh

Wati. 2018. Perpustakaan digital dalam temu kembali informasi dengan opac. Jurnal Ilmu

Perpustakaan dan Informasi. Vol 3(1). Diakses 20 Juli 2020 dari http://jurnal.uinsu.ac.id/index.php/jipi/ar ticle/view/1604/1305

Yusrawati. (2017). Strategi pengembangan sistem temu kembali informasi berbasis "image" di perpustakaan perguruan tinggi. Libria, 53-69. 